\title{
História do cuidado à mulher na Maternidade Carmela Dutra, Florianópolis-SC, Brasil (1956-2001)
}

\author{
History of care to women in the Maternity Carmela Dutra, Florianópolis-SC, Brazil (1956-2001) \\ Historia del cuidado a la mujer en la Maternidad Carmela Dutra, Florianópolis-SC, Brasil (1956-2001)
}

\section{Vitoria Regina Petters Gregório', Maria Itayra Coelho de Souza Padilha"}

'Universidade Federal de Santa Catarina, Departamento de Enfermagem. Florianópolis-SC, Brasil.

"Universidade Federal de Santa Catarina, Departamento de Enfermagem, Programa de Pós-Graduação em Enfermagem. Pesquisadora do CNPq. Florianópolis-SC, Brasil.

\author{
Submissão: 04-05-2011 Aprovação: 23-10-2012
}

\section{RESUMO}

Este estudo objetivou analisar as práticas de cuidado desenvolvidas pelas enfermeiras à mulher na Maternidade Carmela Dutra, de Florianópolis, Santa Catarina, no período de 1956 a 2001. Pesquisa qualitativa com abordagem sócio-histórica. Foram entrevistadas nove enfermeiras, utilizando-se a técnica de História Oral Temática. Os dados foram categorizados utilizando-se análise de conteúdo temática, com base no referencial foucaultiano. Emergiram quatro categorias: Contexto da Maternidade; Práticas de cuidado à mulher na admissão; Práticas de cuidado à mulher no parto e Práticas de cuidado à mulher no puerpério. Concluiu-se que o cuidado prestado à mulher na maternidade foi exercido por religiosas e parteiras, por enfermeiras leigas e por enfermeiras obstétricas, numa trajetória que vai do cuidado laico ao profissional, entrelaçado por relações de saber-poder demarcadas por lutas e resistências ao poder médico hegemônico da época.

Descritores: Enfermagem Obstétrica; História da Enfermagem; Saúde da Mulher.

\section{ABSTRACT}

This study examines the practices of care developed by nurses to women at Maternity Carmela Dutra, Florianópolis, Santa Catarina state, Brazil, in the period 1956 to 2001. It is a qualitative research with socio-historical approach. Nine nurses were interviewed using the technique of thematic oral history. The data were categorized using thematic content analysis and based on the foulcaultian theoretical framework. Four categories emerged: Context of Motherhood; care practices to women on admission; care practices to women on childbirth and care practices to women on puerperium. It was concluded that the care provided to women at the Maternity has been exercised by religious and midwives, nurses and lay nurse midwives, a path that goes from laic to professional care, intercalated with knowledge-power relationships marked by struggles and resistances to doctor's hegemony of that time.

Key words: Obstetrical Nursing; Nursing History; Obstetrics; Women's Health.

\section{RESUMEN}

Este estudio tuvo como objetivo analizar las prácticas de cuidado desarrolladas por las enfermeras a la mujer en la Maternidad Carmela Dutra, de Florianópolis, estado de Santa Catarina, Brasil, durante el período de 1956 a 2001. Investigación cualitativa con abordaje socio-histórico. Fueron entrevistadas nueve enfermeras, utilizando la técnica de Historia Oral Temática. Los datos fueron categorizados utilizando análisis de contenido temático, con base en el referencial foucaultiano. Emergieron cuatro categorías: Contexto de la Maternidad; Prácticas de cuidado a la mujer en la admisión; Prácticas de cuidado a la mujer en el parto y Prácticas de cuidado a la mujer en el puerperio. Se concluyó que el cuidado brindado a la mujer en el maternidad fue ejercido por religiosas y parteras, por enfermeras laicas y por enfermeras obstétricas, en una trayectoria que va del cuidado laico al profesional, entrelazado por relaciones de saber-poder demarcadas por luchas y resistencias al poder médico hegemónico de la época.

Palabras clave: Enfermería Obstétrica; Historia de la Enfermería; Obstetricia; Salud de la Mujer.

Extraído da Tese de Doutorado "A historicidade das práticas de cuidado na Maternidade Carmela Dutra (1956-2001)", apresentada, em 2011, ao Programa de Pós-Graduação em Enfermagem da Universidade Federal de Santa Catarina. Florianópolis-SC, Brasil. 


\section{INTRODUÇÃO}

A história da assistência à mulher durante o parto, em seus encontros e desencontros entre parteiras, médicos e enfermeiras, vem sofrendo transformações sociais, culturais e políticas importantes ao longo dos séculos. Revisitando a história da assistência ao parto observa-se que estes eram realizados no domicílio, por mulheres conhecidas popularmente como aparadeiras, comadres ou mesmo parteiras leigas, passando posteriormente a serem atendidos em instituições de saúde por médicos e enfermeiras obstétricas.

Em Florianópolis-SC, a assistência ao parto acontecia no domicílio até o início do século XX, modificada com a inauguração da primeira maternidade denominada Maternidade de Florianópolisa, pelo Decreto n. 1832, de 31 de janeiro de 1925, do Governo do Estado, sob a responsabilidade da Associação Irmão Joaquim. Em junho de 1926 começou a receber as primeiras parturientes, embora a data oficial de inauguração tenha sido 06 de fevereiro de $1927^{(1)}$.

Considerando o crescimento da população urbana foi elaborado um projeto político para construir a segunda maternidade da cidade, que objetivava atender também a população indigente. A Maternidade Carmela Dutra (MCD) recebeu esse nome em homenagem a Carmela Leite Dutra, esposa do então presidente do Brasil, General Eurico Gaspar Dutra (1946-1951). Foi inaugurada em 03 de julho de 1955, começando a atender as parturientes e os recém-nascidos somente em fevereiro de 1956, devido à carência de recursos humanos. Subordinada à Secretaria de Saúde e Assistência Social, sua administração e organização ficou sob responsabilidade das Irmãs da Divina Providência, sendo Irmã Hortênsia a Madre Superiora(2-3).

Este artigo tem como objetivo analisar as práticas de cuidado desenvolvidas pelas enfermeiras à mulher na MCD no período de 1956 a 2001. A escolha do marcador do tempo contemplou o período inicial de 1956 com o ingresso da primeira enfermeira na MCD, Irmã Cacildab, (seu nome de nascimento é Ottille Hammes), e o período final de 2001 com a posse da primeira enfermeira como diretora da MCD, Doutora Evanguelia Kotzias Atherino dos Santos.

\section{METODOLOGIA}

Trata-se de pesquisa qualitativa com abordagem sócio-histórica. Para a coleta de dados foi utilizada a técnica da história oral temática pela escassez de informações escritas referentes à participação das enfermeiras nas práticas de cuidado na MCD. As falas das enfermeiras foram necessárias para revelar os eventos e práticas de cuidado no período histórico estudado. História oral temática é um gênero da história que tem como objetivo abordar assuntos específicos e previamente estabelecidos ${ }^{(4)}$.
Os sujeitos da pesquisa foram nove enfermeiras que trabalharam na MCD no período entre 1956 e 2001, as quais foram entrevistadas de fevereiro a julho de 2009 pela técnica bola de neve ${ }^{(5)}$, até a saturação dos dados. Na entrevista foram abordadas questões sobre: contexto da maternidade, estrutura física e práticas de cuidados à mulher parturiente e ao recém-nascido internados na MCD. O tempo médio das entrevistas foi de três horas, em locais de escolha das entrevistadas. As entrevistas foram gravadas por meio digital e, posteriormente, foram transcritas e validadas pelos sujeitos, de julho a setembro de 2009. Foram utilizadas também fontes documentais: jornais, livros de passagem de plantão e fotos. Os dados foram analisados pela Análise de Conteúdo Temática de Minayo ${ }^{(6)}$.

O referencial teórico-filosófico de Michel Foucault estabeleceu um diálogo com as bases filosóficas e históricas contemporâneas ao pensar os acontecimentos do passado, na perspectiva de encontrar luz para interpretar a história do presente e vislumbrar neste estudo o poder-saber das enfermeiras em suas práticas de cuidado à mulher(7). A análise dos dados revelou quatro categorias: $\mathrm{O}$ contexto da Maternidade Carmela Dutra; As práticas de cuidado à mulher na admissão; As práticas de cuidado à mulher no parto e As práticas de cuidado à mulher no puerpério. O projeto de pesquisa foi avaliado pelo Comitê de Ética em Pesquisa com Seres Humanos da UFSC, sendo aprovado por parecer exarado no processo protocolado sob o $n^{\circ}$ 003/09. Os participantes assinaram o Termo de Consentimento Livre e Esclarecido, a Carta de Cessão da entrevista e o uso de imagens fotográficas, de acordo com as Resoluções 196/96 e 251/97 do Conselho Nacional de Saúde. Para o presente estudo, as entrevistadas concordaram que seus nomes fossem citados. Além disso, ao lado do nome de cada uma delas foi incluído o ano de sua inserção na MCD.

\section{RESULTADOS E DISCUSSÃO}

A análise e a discussão dos dados são abordadas em quatro categorias referentes ao contexto e às práticas realizadas pelas enfermeiras no cuidado à mulher na MCD. Em tal sentido, será apresentada a evolução histórica dessas práticas, sem descrever a história de forma linear, mas uma crítica apontando as rupturas que ocasionaram as transformações.

\section{A. $O$ contexto da Maternidade Carmela Dutra}

A organização do cuidado de enfermagem na MCD de fevereiro de 1956 até 1968 ficou sob a responsabilidade das Irmãs da Divina Providência que organizavam os serviços administrativos e as práticas de enfermagem da forma como os realizavam em outros hospitais. Elas eram a autoridade que detinha o poder-saber "fabricando" pessoas regidas pelo poder disciplinar ${ }^{(8)}$. A partir de abril de 1956, com a inserção da primeira enfermeira, Irmã Cacilda, foi possível melhorar a

a. Em 30 de maio de 1948 a Maternidade receberia o nome do Dr. Carlos Corrêa, em homenagem ao seu diretor clínico, falecido em 29 de novembro de 1947.

b. No decorrer do estudo, Ottille Hammes será nominada Irmã Cacilda, seu nome como religiosa na Congregação das Irmãs da Divina Providência. 
qualidade das práticas de cuidado de enfermagem, como se percebe em seu depoimento:

Formar enfermeira foi uma proposta da congregação das Irmãs da Divina Providência influenciadas pelo então Cardeal do Rio de Janeiro, Dom Jaime de Barros Câmara. E também por exigência da Secretaria da Saúde, porque até então quem exercia a enfermagem eram as práticas de enfermagem, parteiras e atendentes. (Irmã Cacilda,1956)

A qualificação dos trabalhadores da saúde era uma Política de Estado que visava à qualidade da assistência e a manutenção dos hospitais. Porém, a MCD continuou com apenas uma enfermeira no quadro funcional até 1972, pois o Estado de SC na década de 1950 era pouco atrativo, devido aos baixos salários. O enfermeiro recebia apenas um salário mínimo mensal ${ }^{(9)}$. Os dados estatísticos demonstram que, em 1956, havia no Brasil 4.517 enfermeiros e 39 escolas de enfermagem $^{(10)}$. Essa realidade se refletia na MCD na dificuldade de ter enfermeiras no seu quadro funcional, pois no Estado não havia escola de formação dessas profissionais. Foi na gestão da Enfermeira Irmã Cacilda na ABEN- SC que tal cenário começou a modificar-se. A ABEN-SC foi criada em março de 1962, quando havia no Estado apenas 11 enfermeiras. Irmã Cacilda foi diretora na primeira gestão, reivindicando a reclassificação do enfermeiro para o nível técnico-científico. Após um ano foi aprovada a Lei 3.175/63, que tornava realidade essa reivindicação ${ }^{(9,11)}$. A aprovação dessa lei foi um marco para a enfermagem de Santa Catarina, motivando a vinda de enfermeiras formadas no Rio Grande do Sul para trabalhar nos hospitais de Florianópolis e, consequentemente, melhorar a qualificação dos profissionais, como podemos observar:

Em 1963 deu pra negociar e vieram cinco enfermeiras para o Hospital Infantil: a Eloita Pereira Neves, a Irmgard, a Nelcy Terezinha, a Nilza Paim e a Eleonor Caon. (Irmã Cacilda, 1956)

Irmã Cacilda destacou-se na organização e na estruturação da enfermagem na MCD, inaugurando uma trajetória no cuidado de enfermagem à mulher parturiente e puérpera, de maneira diferenciada e apoiada em princípios científicos e legais, o que não era comum à época.

Quem tomava decisão era a madre superiora e o médico (diretor) [...]. Nós nos incomodávamos muito quando queríamos mudar alguma coisa [...]. A Madre Superiora exigia que tratássemos bem o Diretor, porque, para ela, ele era a pessoa mais importante, aí teve muitas brigas porque eu não me submetia. (Irmã Cacilda, 1956)

A história das práticas de cuidado na MCD foi construída a partir das lutas dessa religiosa, tendo como pano de fundo o poder-saber institucionalizado. Mas a enfermeira não deixava prevalecer o discurso de verdade histórico-política veiculado na instituição. A enfermeira utilizava as armas do discurso crítico de cunho científico visando à qualidade das práticas de cuidado à mulher parturiente e à puérpera. Essa história construída pela enfermeira Irmã Cacilda pode ser interpretada como movimento de luta e resistência ao poder-saber médico institucionalizado, que não reconhecia o saber-poder da enfermeira.

Em 1968 a Congregação das Irmãs da Divina Providência deixou a MCD em razão do término do contrato com o Estado. Naquela ocasião, a enfermeira Nilsa Borges Paim havia pedido transferência do Hospital Infantil $(\mathrm{HI})$ para compor o quadro da enfermagem na MCD, permanecendo como única enfermeira após a saída da Irmã Cacilda. Sua inserção no quadro funcional naquele momento histórico produz uma mudança na organização do cuidado: a enfermagem organizada por enfermeira religiosa é substituída pela enfermagem organizada por enfermeira leiga.

Em relação à estrutura física, na sua inauguração a MCD foi divulgada pelos jornais da época como um grande e ousado estabelecimento hospitalar que viria atender a especialidade da obstetrícia ${ }^{(2-3)}$.

Naquele tempo só havia enfermaria e sala de parto. As gestantes ficavam na enfermaria. Fazia a internação e ficava no leito e lá eram acompanhadas pela parteira que as levava pra sala de parto quando tava pra ganhar. (Irmã Cacilda, 1956)

No entanto, a estrutura ficou deficitária, motivada pela grande demanda e por ser a única maternidade em Florianópolis que atendia parturientes indigentes e da previdência social. Na internação, as mulheres eram recebidas e acompanhadas pelas parteiras.

Só havia duas maternidades na cidade, e num determinado tempo uma delas parou de atender e só ficou a Carmela Dutra. Tinha dias que chegávamos de manhã e tinha paciente deitada em sofá, ganhando neném na cama, e as mesas de parto ocupadas. Chegamos ao ponto de encontrar pela manhã duas pacientes na mesma cama, de tanta gente que ganhava, não tinha mais onde colocar. (Sônia, 1979)

Esse depoimento mostra a dimensão do problema que a enfermeira enfrentava por causa da estrutura física insuficiente para atender a grande demanda de parturientes. Assim, para melhor acolher a mulher, a sala de parto foi reestruturada ao longo do tempo, passando a ter outras salas para acolhimento.

Era a sala de admissão, o pré-parto e a sala de parto. (Nilsa, 1968)

Então não tinha leito de recuperação pós-parto, as parturientes saíam da mesa de parto e iam direto para o Alojamento Conjunto, elas não ficavam o período de Greenberg no Centro Obstétrico. (Odaléa, 1985)

Foi em 1996, quando conseguimos o título Hospital Amigo da Criança, que acabou o berçário. Então essa área, que era grande, transformou-se em pré-parto e o antigo 
pré-parto ficou pós-parto. Eu nem consigo imaginar como é que era isso, porque hoje a estrutura do setor de admissão, pré-parto e berçário, tudo isso, hoje é centro obstétrico. (Odete, 1987)

As reformas da MCD centravam-se principalmente na área física, não havendo modificação significativa nos procedimentos realizados, o que só foi possível com a implementação das políticas públicas que provocaram, além de alterações profundas na área física, mudanças nas práticas de cuidado à mulher. Para acompanhar as políticas de saúde visando à humanização da assistência, a enfermeira necessitou treinar e remanejar os funcionários do berçário para outras unidades, reavaliando a forma de cuidar.

[...] para a enfermagem foi um momento difícil, a extinção do setor, foi muito traumatizante para as pessoas que trabalhavam nesse setor. Acabou o que elas faziam uma vida inteira. [...]. Foi muito boa essa mudança, foi muito visível, claro que houve dificuldades com o funcionário. Foi necessário todo um trabalho de treinamento [...] para cuidar da mãe e do filho juntos. (Odete, 1987)

Observa-se que os profissionais estavam preocupados em melhorar a qualidade da assistência, e para isso a enfermagem teve de incorporar novos saberes. Com o apoio do Ministério da Saúde (MS), em 1996, foi implementada na MCD a Iniciativa Hospital Amigo da Criança com o objetivo de promover, proteger e apoiar o aleitamento materno ${ }^{(12)}$.

Resumidas a organização de pessoal e a estrutura física da MCD, passamos a apresentar as práticas de cuidados à mulher no momento de sua admissão na maternidade.

\section{B. As práticas de cuidado à mulher na admissão}

A admissão era o local onde a mulher era recebida e se submetia aos procedimentos formais para a sua internação, e alguns deles permaneceram inalterados por todo o período estudado. As rotinas estabelecidas para as práticas de cuidado aconteciam em espaços setorizados, e como consequência eram fragmentadas e realizadas por diferentes profissionais, dependendo do espaço em que a parturiente se encontrasse. Durante algumas décadas os hábitos de higiene e alimentação da maioria das mulheres atendidas na MCD refletiam a sua situação econômica, como se vê na fala abaixo:

A maioria das pacientes não pagantes, ditas indigentes, vinham em estado lastimável. Sujas, com mau cheiro, sem dentes ou com dentição muito prejudicada, desnutridas; algumas com piolhos e com bicho de pé. A primeira coisa após o exame era mandá-las para o banho. Recebiam uma toalha e camisola. (Ana Maria, 1973)

Percebe-se que na hospitalização as mulheres se submetiam a rotinas que na óptica dos profissionais visava a seu bem-estar e acolhimento afetuoso. Por várias décadas, essas rotinas foram realizadas pela parteira com o auxilio da atendente, pois não havia médico de plantão, apenas de sobreaviso, e era chamado somente quando necessário. Em vista disso, a parteira assume um papel essencial para o cuidado à mulher, como fica evidente nos depoimentos abaixo:

A parteira examinava e definia se ficava internada ou não. Se internava, fazia os preparativos, como tricotomia na região pubiana, lavagem intestinal. [...] mas era feito com muito carinho. (Irmã Cacilda, 1956)

A admissão era feita pelas parteiras, naquele tempo não tinha os residentes, não tinha médicos dentro da sala de parto, até muitas vezes era difícil encontrar um médico pra ir lá atender a paciente quando era um caso mais grave. Eles ficavam em casa, não tinha plantão na maternidade. (Doraci, 1976)

Com o passar do tempo, os médicos se apropriaram do saber-fazer da parteira e ampliaram seu espaço. Houve, portanto, a transição quanto aos profissionais que realizavam a admissão, passando das parteiras para o médico. Alguns procedimentos para internar a parturiente permaneceram, como, por exemplo, a tricotomia da região pubiana e perineal e a lavagem intestinal. Cabe ressaltar que esses procedimentos, quando foram implementados na MCD, estavam apoiados em recomendações dos tratados de obstetrícia ${ }^{(13)}$. Mas também não podemos deixar de observar que a manutenção dessas rotinas contraria a evolução dos conhecimentos na área, negligenciando as evidências científicas.

Podemos observar correlação de forças entre políticas de saúde baseadas em evidências científicas e outras condutas inapropriadas na assistência ao parto ${ }^{(13)}$.

Durante o período de estudo nota-se que apenas a forma de realizar tais procedimentos sofreu modificações com a inserção de enfermeiras e enfermeiras obstétricas na sala de parto. Com o seu saber formal, elas questionaram as práticas de cuidado instituídas na admissão e provocaram mudanças para melhorar a qualidade da assistência, como se vê no depoimento das enfermeiras obstetras:

Em relação às técnicas de enfermagem, a que nos deixou realmente chocadas foi a do enema. Na época, era feito com aquele caneco de dois litros de água morna, mais a adição de sabão de coco líquido, preso ao suporte de soro. O problema maior residia no uso da sonda retal: era apenas uma sonda, usada para todas as pacientes admitidas naquele dia. Para receber o material necessário para modificá-las, as enfermeiras da maternidade se dispuseram a dar uma aula sobre o assunto para o chefe do almoxarifado, que finalmente liberou o pedido. (Ana Maria, 1973)

A tricotomia, eu lembro quando eu cheguei lá, eram giletes, aqueles aparelhos antigos de barba, [...] deixavam de molho no germikil e usavam um aparelho para todas as parturientes, até acabar o fio da gilete (risos). Eu comecei a organizar o serviço, esterilizar o aparelho em autoclave separadamente, pedir mais aparelhos de gilete e usar lâmina nova. (Odaléa, 1985) 
Os problemas relacionados ao controle de infecção eram os que mais chamavam a atenção das enfermeiras e enfermeiras obstetras. Elas precisavam evitar os efeitos nocivos das práticas instituídas. Para evitar infecções, as enfermeiras propunham modificações, mas não era fácil. Elas precisavam mostrar um saber que justificasse tais mudanças. Para isso, utilizaram uma das estratégias do poder-saber - a disciplina ${ }^{(8)}$ para organizar as práticas de cuidado desenvolvidas na MCD. Outro aspecto a ser discutido e que se percebe na falas dos sujeitos do estudo é a incessante busca para implementar novos cuidados/tecnologias, voltados para a humanização.

A gente queria imprimir esses princípios da humanização, das práticas recomendadas pela OMS. Já durante minha gestão como diretora, em 2001, comecei a trabalhar isso, para o Prêmio Galba de Araújo [...]. Mas ali esbarrava com esse poder médico. Em relação à tricotomia, por exemplo, não havia necessidade, de acordo com as evidências científicas, de realizar em todas as gestantes. Fiz um decreto (risos). Mas eles reagiram, fizeram abaixo-assinado, trouxeram uma justificativa absurda. Daí a gente batia de frente também com os obstetras nessas políticas. (Evanguelia, 1976)

Instituído pelo Ministério da Saúde brasileiro em 1999, o Prêmio Galba de Araújo tem como objetivo reconhecer instituições públicas e privadas integrantes da rede do Sistema Único de Saúde (SUS), que se destacavam pelas inovações voltadas à humanização do atendimento obstétrico e neonatal e incentivo ao parto normal ${ }^{(14)}$.

Com o crescente número de mulheres que procuravam a MCD, a enfermagem dependia de rotinas que gerassem eficiência na organização dos serviços. Porém, não conseguia instituir práticas de cuidado personalizadas ou as preconizadas pela Organização Mundial da Saúde ${ }^{(31)}$ que recomendava as tecnologias para atenção ao parto e nascimento, classificando as práticas com base em evidências científicas em quatro grupos: Grupo A, práticas benéficas a serem incentivadas; Grupo $B$, práticas danosas ou ineficazes a serem abandonadas; Grupo $C$, práticas com evidências insuficientes, que demandam mais pesquisas; e Grupo D, práticas que têm sido utilizadas de maneira inadequada. Algumas vezes as enfermeiras se defrontavam com resistências que obstavam a implementação de estratégias para a humanização das práticas de cuidado à mulher na MCD, como, por exemplo, a retirada de determinadas rotinas do grupo $B$, na admissão da mulher.

Questiona-se: por que é "simples" a exclusão dessas rotinas para as enfermeiras e tão difícil para os médicos? Uma possibilidade é que implicaria perda de poder e controle do processo de parturição, modificando as referências do papel do médico na maternidade ${ }^{(15)}$. Ao longo do período histórico estudado, as rotinas na admissão da mulher defendidas pelos obstetras da MCD permaneceram inalteradas, identificando um poder-saber dominado pela hegemonia médica, embora as enfermeiras tenham conseguido modificar algumas dessas práticas.

\section{As práticas de cuidado à mulher no parto}

$\mathrm{Na}$ sala de parto, assim como na admissão, os poderes se confrontavam: o poder pelo fazer da parteira, o poder pelo saber da enfermeira e o poder médico hegemônico. Assim, as práticas de cuidado à mulher aconteciam conforme o movimento de forças que prevaleciam naquele espaço. $\mathrm{O}$ atendimento às mulheres na sala de parto antes da inserção do residente era realizado em sua maioria pelas parteiras, em escala de serviço nas 24 horas, enquanto os médicos, por seu reduzido número, só eram chamados quando as parteiras julgavam necessário.

Mas a maioria dos partos era feita pelas parteiras. Tanto o particular como o de caso social, considerado indigente. (Nilsa, 1968)

As parteiras faziam todo o preparo, e elas usavam ocitocina para indução do parto. O médico prescrevia depois. Olha, às vezes eram partos difíceis, então elas paravam e iam depressa chamar o médico. [...], mas tinha bastante dificuldade, porque havia poucos médicos e eles não faziam plantão; às vezes até pra uma cesárea era procurado um, procurado outro, e não se encontrava ninguém.[...] anestesista pra fazer a cesariana tinha. Ele morava ali perto, aí ele vinha. (Doraci, 1976)

Os médicos definiam o fazer das parteiras. Esse saber-fazer das parteiras aos poucos foi incorporado pelos médicos e pelas enfermeiras obstétricas, cujo poder-saber levou-as a ocupar os espaços na sala de parto. Assim, as práticas de cuidado realizadas pelas parteiras de maneira informal foram incorporadas por outros profissionais da instituição, adquirindo um caráter dito "científico". No entanto, esse discurso veiculado como "científico" nem sempre acompanhava o desenvolvimento da prática obstétrica baseada em princípios humanísticos, apoiada política e tecnicamente pela OMS e pelo $\mathrm{MS}^{(16)}$. A mulher deveria aceitar a ordem disciplinar das práticas de cuidado estabelecidas pela instituição, como no momento da internação, que ela deixava fora da sala de parto os seus pertences, seus familiares, sua cultura e sua identidade.

Na sala de parto não era permitido acompanhante, pelo menos na minha época, e ninguém nos solicitava para ficar junto e assistir o parto. (Nilsa, 1968)

As mulheres sofreram por muito tempo com a ausência de integração da família aos cuidados. Essa realidade na sala de parto da MCD só foi modificada com a Lei $n^{\circ} 11.108$, de 7 de abril de 2005, que garantia o direito à presença de um acompanhante de escolha da mulher durante o trabalho de parto, parto e pós-parto imediato ${ }^{(17)}$.

No início dos anos 1970, a enfermeira chefe da unidade de internação também era responsável pela chefia da sala de parto. Com a contratação de mais enfermeiras na década de 1980 para a MCD, a enfermeira pôde ficar responsável por apenas um setor. Convém salientar que a primeira enfermeira obstétrica a atuar na sala de parto da MCD foi Ana Maria Westphal Batista da Silva, em 1973, e após doze anos, em 1995 assume a segunda enfermeira obstétrica, Odaléa Maria Brüggemann. Outras enfermeiras generalistas assumiram a chefia da sala de 
parto durante esse período, como, por exemplo, Evanguelia Atherino Kotzias dos Santos, Sônia Maria de Castilhos e Ercília Rosa Machado. Mesmo com muitas responsabilidades, a enfermeira não ficava restrita à administração dos setores. Realizava cuidados voltados para a humanização da assistência à mulher e à equipe de saúde, como podemos observar nestes depoimentos:

Não fazia partos, não era enfermeira obstétrica, mas dentro do possível cobrava se não estavam fazendo toque demais. Além de supervisionar o cumprimento das rotinas de medicação, limpeza etc., ficava ao lado das pacientes, conversando, tranquilizando, monitorando batimentos cardíacos e apoiando na hora do parto. Quando o neném precisava ser levado para o berçário de alto risco, eu subia para trazer notícias. (Sônia, 1979)

Em relação as parturientes, iniciamos campanha pela preservação da privacidade. Trouxemos biombos, reintroduzimos a duras penas o ato de cobri-las durante o exame ginecológico. (Ana Maria, 1973)

Na sala de parto a enfermeira realizava práticas de cuidado além da técnica e das suas atividades administrativas, indo ao encontro do que posteriormente foi preconizado pelo MS e pela $\mathrm{OMS}^{(18)}$ para a atenção obstétrica e neonatal, realizando assistência humanizada à mulher no acompanhamento do parto. No entanto, o cotidiano da enfermeira na sala de parto acontecia com muita dificuldade, em razão de problemas na estrutura física da maternidade e falta de material e pessoal, como atestam os depoimentos a seguir:

Era um trabalho desgastante e que não tinha condições adequadas. Nós tínhamos uma média de setecentos partos por mês. Então de manhã na sala de parto, tinha duas parturientes em cada leito. Pacote de parto tinha que dividir para três partos. (Odaléa, 1985)

Trabalhar na sala de parto exigia da enfermeira conhecimento de administração do tempo, do material e dos profissionais de enfermagem para atender todas as mulheres que procuravam os serviços da MCD, proporcionando a melhor assistência possível nesse contexto. Observa-se a concentração de trabalho na sala de parto, a produção de trabalho em grande escala, utilizando-se ao máximo dos espaços e dos corpos, "tornando-os dóceis" e resultando em uma racionalidade econômica ou técnica, reproduzindo a ordem social capitalista $^{(19: 119)}$. Além de se preocupar em cuidar da mulher em trabalho de parto, a enfermeira proporcionava treinamento para os profissionais de enfermagem, atentando para os riscos de contaminação em defesa da saúde do trabalhador.

Havia apenas uma pia no pré-parto. Ali era lavado o material, as luvas, era despejada a solução onde eram colocados os espéculos. Estava se iniciando o uso de esterilizantes químicos e também detectamos problemas com relação ao seu uso. Assim, dividimos os funcionários em pequenos grupos e fizemos treinamentos curtos e repetidos abordando esses aspectos. Os resultados foram positivos. Era necessário colocar avental e pró-pé para entrar na sala de pré-parto; trocar a roupa de cama mais vezes; controle da limpeza, esterilização e armazenamento de material da sala de parto; cuidado especial com as comadres, usadas por diversas parturientes. (Ana Maria, 1973)

Ao priorizar o trabalho de administração, a enfermeira fortalecia o seu papel de trabalhadora intelectual da enfermagem. Na sala de parto havia a preocupação com o ambiente, e ela utilizava seu saber-poder para identificar os problemas e realizar as mudanças necessárias e possíveis, procurando proporcionar um espaço seguro para a mulher e para a equipe de enfermagem.

A palavra controle traz consigo a relação de saber-poder ${ }^{(19)}$. As enfermeiras promoviam relação harmoniosa, técnica e ética para proteger a saúde da mulher e da equipe de enfermagem. A infecção hospitalar constitui um problema de saúde pública, mostra-se como um desafio constante para as enfermeiras e uma ameaça para a mulher hospitalizada. Nesse contexto, o saber sobre a infecção hospitalar e as ações para preveni-la conferem à enfermeira poder para melhorar as práticas de cuidado, tanto para a mulher quanto para os profissionais de enfermagem.

\section{As práticas de cuidado à mulher no puerpério}

Na MCD, até 1996, após o parto a mulher era levada para a unidade de internação, onde continuava separada de sua família e de seu filho recém-nascido; o contato só era permitido em horários predeterminados. As práticas de cuidado eram realizadas por atendentes de enfermagem treinadas pelas irmãs da Congregação da Divina Providência, principalmente pela Irmã Cacilda. Essas unidades eram enfermarias com 11 leitos cada uma, totalizando 44 leitos.

Eu treinei tudo que era preciso: os cuidados de enfermagem e sinais vitais. Elas chegavam sem saber nada. A gente morava lá, não tinha horário pra nada. (Irmã Cacilda, 1956)

As atendentes seguiam uma disciplina estabelecida pelas Irmãs da Divina Providência. O treinamento a que eram submetidas visava não somente a aumentar as habilidades, mas torná-las úteis para a instituição, formando "uma política das coerções que são um trabalho sobre o corpo, uma manipulação calculada de seus elementos, de seus gestos, de seus

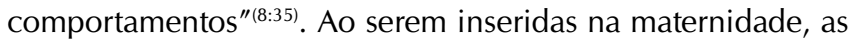
enfermeiras assumem a função de administrar e supervisionar o trabalho daquelas atendentes.

Eram registradas no prontuário pelas atendentes: as ocorrências mais graves, sinais vitais e medicação que era administrada. Os prontuários individuais ficavam no posto de enfermagem. A enfermeira, quando passava visita com o médico, levava os prontuários. (Irmã Cacilda, 1956)

Observa-se que as ações da enfermagem e da enfermeira 
eram regidas pelo poder disciplinar, com registro contínuo detalhando os acontecimentos para fornecer elementos ao poder-saber médico. As enfermeiras também tomavam para si a responsabilidade de determinadas práticas próprias do profissional médico:

Algumas vezes as puérperas pediam remédio pra dormir, daí tinha que ligar pro médico que tava de plantão. [...] falava por telefone, ele dizia qual remédio dar, daí no outro dia tinha que lembrar pra ele prescrever. (Nilsa, 1968)

Avaliando essa conduta, percebe-se que a enfermeira se submetia ao poder-saber dos médicos em relação de docilidade-utilidade. Essa "mecânica do poder"(19) define a ação da enfermeira e a orienta sobre como agir. Havia também uma submissão dos profissionais de enfermagem ao saber-poder das enfermeiras que organizavam as práticas de cuidado.

A atendente que cuidava da enfermaria tinha obrigação, de 15 em 15 minutos, de verificar o forro e ver a pressão. A higiene perineal era feita com uma pinça, com gaze, colocava a comadre e derramava água e limpava. E depois elas iam pro chuveiro no segundo dia. Banho de leito só no primeiro dia da cesariana. (Nilsa, 1968)

O curativo da episiorrafia era feito com mercúrio. (Doraci, 1976)

Uma mudança significativa foi nos cuidados com anestesia raque. Eram 24 horas deitada sem travesseiro [...] a evolução de 24 para 12 horas e agora para 8 horas [...]. Na incisão da cesárea tinha um curativo fechado, só podia abrir depois com 72 horas. Então, em determinado momento também se abriu o curativo após 24 horas, ela tomava o banho normal e só se fazia o curativo novo. Depois de um tempo não se fazia mais o curativo. [...] agora após 24 horas retira e não se coloca nada, fica a incisão exposta. Tudo são evoluções. [...] então, com o Hospital Amigo da Criança a permanência passou para 48 horas, tanto o parto quanto a cesárea. (Odete, 1987)

Havia normas estabelecidas para realizar os cuidados à mulher no puerpério, além de vigilância constante, e esses são alguns dos mecanismos disciplinares que ocorriam no contexto da MCD. Essa disciplina podia ter como objetivo evitar infecção hospitalar e organizar os serviços para melhor aproveitar a força de trabalho da enfermagem. Tal realidade reflete a ordem estabelecida na instituição. A incorporação de novos saberes na área da saúde confere poder aos profissionais para modificar a assistência à mulher puérpera.

Os depoimentos revelam modificações de algumas práticas de cuidado realizadas no período estudado. Rotinas estabelecidas como verdades foram questionadas, mas só foram modificadas por meio de um poder-saber: algumas respaldadas por políticas públicas, outras pelas evidências científicas que visavam à qualidade das práticas de cuidado oferecidas às mulheres. demonstrando um pensamento crítico reflexivo, a enfermeira percebe a mulher como sujeito do cuidado. Modificar a forma de cuidar foi difícil na MCD, as mudanças foram lentas. Normas e rotinas conhecidas se traduzem em poder, e a mudança tira o profissional da sua área de conforto, desprovendo-o do saber e interferindo no seu poder. Mas nem sempre o saber da enfermeira possibilitou romper com verdades estabelecidas pelo poder médico, como indicam estes depoimentos:

Uma rotina desnecessária, mas que continua até hoje, é uso da sonda vesical na cesariana. A paciente fica com a sonda que é retirada após 8 horas, no momento em que vai para o banho. Só que para a cesárea seria desnecessário o uso da sonda. A enfermagem acha cômodo, mais fácil esvaziar uma bolsa do que estar colocando a comadre várias vezes. Se formos fazer uma enquete com a enfermagem para saber o que ela acha, com certeza dirá que é ótimo, mas nós temos que analisar se é benéfico ou não para a paciente. (Odete, 1987)

Nesse período histórico, observa-se que as ordens estabelecidas para as práticas de cuidado construíram discursos de verdade. As enfermeiras algumas vezes demonstraram resistência e lutaram contra essa ordem, fundamentando-se no saber científico e humanizado, amparadas principalmente pelas recomendações do MS e da OMS; outras vezes se submeteram ao poder médico como fundamento de verdade, sem questionar.

A noção do poder-saber é apontada como relação de força e movimento. $\mathrm{O}$ referencial foucaultiano mostra outro modo de perceber o poder sob a óptica da positividade. Não resulta de uma conquista, mas de uma luta contínua e difusa; não apresenta uma configuração fixa, permitindo inversões nas suas relações ${ }^{(8)}$. Para as enfermeiras, essas lutas resultaram em modificações nas práticas de cuidado focando a atenção à mulher como sujeito de cuidado, em todo o processo da admissão, parto e puerpério vividos na MCD.

\section{CONSIDERAÇÕES FINAIS}

Este estudo possibilitou conhecer o cotidiano das práticas exercidas pelas enfermeiras no cuidado dispensado à muIher na MCD no período de 1956 a 2001. Também iluminou os bastidores, revelando como se constituíram essas práticas e as relações de saber-poder. A história das enfermeiras foi construída a partir da Irmã Cacilda e pode ser interpretada como movimento de luta e resistência ao poder-saber institucionalizado.

Essas lutas foram evidenciadas ao longo do período estudado; as enfermeiras questionaram verdades estabelecidas que foram modificadas por meio do poder-saber respaldado tanto pelas políticas públicas quanto pelas evidências científicas que visavam à qualidade das práticas de cuidados às mulheres. Paralelamente houve o fortalecimento da identidade das enfermeiras e sua contribuição para construir a profissão, demonstrando a sua participação ativa no processo sócio-histórico, político e cultural na MCD. 
Nesse contexto da prática de cuidado as relações de saber-poder ocorreram nos microssistemas, mostrando como o poder é flexível e maleável, dependendo de suas forças. As enfermeiras tanto exerceram o poder como também sofreram sua ação(20).

As relações de saber-poder exercidas entre enfermeiras e médicos ou entre enfermeiras e profissionais de enfermagem no espaço da MCD possibilitaram rupturas e transformações na prática do cuidado à mulher. Julga-se importante que a profissão conheça e revele os diferentes modos de ser e fazer do passado, tanto quanto as continuidades e descontinuidades, suas resistências e lutas e as redes do saber-poder que permeavam esse contexto. Essas práticas de cuidado desenvolvidas pelas enfermeiras expressavam uma nova ordem e disciplina do cuidado e do desenvolvimento da Enfermagem como uma profissão de cuidado à saúde nos diferentes espaços e tempos históricos.

\section{REFERÊNCIAS}

1. Pereira NV. Associação Irmão Joaquim, 100 anos de Amor ao próximo: histórico da Associação Irmão Joaquim por ocasião do seu centenário 1902-2002. Nereu do Vale Pereira. Florianópolis: Associação Irmão Joaquim; 2002.

2. Inauguração da Maternidade Carmela Dutra. A Gazeta, 1955 Jul 3; p. 3-12

3. Maternidade Carmela Dutra. Diário da Tarde, 1955 Jun 4; p. 29

4. Meihy JCSB. Manual de história oral. São Paulo: Loyola; 2002.

5. Fink A. How to sample in surveys. The Survey Kit (6). Thousand Oaks: Sage; 2003.

6. Minayo MCS. O desafio do conhecimento: pesquisa qualitativa em saúde. São Paulo: HUCITEC-ABRASCO; 2010.

7. Foucault M. Arqueologia do saber. $6^{\mathrm{a}}$ ed. Rio de Janeiro: Forense Universitária; 2007.

8. Foucault M. Microfísica do poder. Rio de Janeiro: Edições Graal; 2012.

9. Gregório VRP, entrevistadora. Cacilda (Irmã da Divina Providência) entrevista concedida ao acervo do Grupo de Estudos de História do Conhecimento da Enfermagem GEHCES/UFSC. Florianópolis: Universidade Federal de Santa Catarina. GEHCES; 2009.

10. Associação Brasileira de Enfermagem. Levantamento dos recursos humanos e necessidades de enfermagem no Brasil 1956-1958. Brasília: ABEn; 1980.

11. Borenstein MS, Padilha MI, Maia AR, Costa E, Gregório VRP, Espíndola AMK. Ottille Hammes: pioneira da Enfermagem catarinense. Rev Bras Enferm 2009;62(2):240-5.

12. Organização Mundial da Saúde. Evidências científicas dos dez passos para o sucesso do aleitamento materno. Brasília: OMS; 2001.

13. Enkin MW, Keirse MJNC, Neilson J, Crowther C, Duley L, Hodnett E, et al. Rotinas hospitalares. In: Enkin MW, Keirse MJC, Neilson JP, organizadores. Guia para atenção efetiva na gravidez e no parto. Rio de janeiro: Guanabara Koogan; 2005. p. 137-43.

14. Ministério da Saúde. Portaria n.2.883/GM de 04 de junho de 1998. Instituiu o Premio Nacional Professor Galba de Araújo [portaria na internet]. Diário Oficial da União 6 jun 1998 [acesso em 12 Jun 2009]. Disponível em: < http://dtr2001.saude.gov.br/sas/PORTARIAS/Port2004/ GM/GM-238.htm >

15. Dias MAB, Domingues RMSM. Desafios na implantação de uma política de humanização da assistência hospitalar ao parto. Ciênc Saúde Coletiva 2005;10(3):699-705.

16. Organização Mundial da Saúde. Maternidade segura: atenção ao parto normal: guia prático. Genebra: Organização Mundial da Saúde; 1996.

17. Brasil. Lei n.11.108, de 7 de abril de 2005. Altera a Lei 8.080, introduzindo o direito ao acompanhante de escoIha durante o trabalho de parto, no parto e no pós-parto imediato. Diário Oficial da União 8 abr 2005. Seção 1. p.1

18. Ministério da Saúde (Brasil). Portaria GM/MS n.569, de 01 de junho de 2000. Institui o Programa de Humanização no Pré-natal e Nascimento no âmbito do Sistema Único de Saúde. Diário Oficial da União 18 ago 2000. p. 112.

19. Foucault M. Vigiar e Punir : nascimento da prisão. Petrópolis: Vozes; 2009.

20. Gregório VRP, Padilha MI. As estratégias do poder no contexto da maternidade Carmela Dutra Florianópolis-SC (1956-1986). Texto \& Contexto Enferm 2012;21(2):277-85. 